\title{
Revision of the genus Dichaetophora Duda (Diptera: Drosophilidae), part I: DNA barcoding and molecular phylogenetic reconstruction
}

Takehiro K. Katoh ${ }^{1,2}$, Ji-Min Chen ${ }^{2}$, Jin-Hua Yang ${ }^{2}$, Guang Zhang ${ }^{2}$, Lu Wang ${ }^{2}$, Awit Suwito ${ }^{3}$, Masanori J. Toda, ${ }^{4, *}$, Ya-Ping Zhang ${ }^{2,5, *}$, Jian-Jun Gao ${ }^{1,2, *}$

${ }^{1}$ Yunnan Key Laboratory of Plant Reproductive Adaptation and Evolutionary Ecology, Yunnan University, Kunming, Yunnan 650091, China

${ }^{2}$ State Key Laboratory for Conservation and Utilization of Bioresources in Yunnan, Yunnan University, Kunming, Yunnan 650091, China

${ }^{3}$ Zoological Division (Museum Zoologicum Bogoriense), Research Center for Biology-LIPI, J1. Raya Jakarta-Bogor Km. 46, Cibinong 16911, West Java, Indonesia

${ }^{4}$ Hokkaido University Museum, Hokkaido University, Nishi 8, Kita 10, Kita-ku, Sapporo 060-0810, Japan

${ }^{5}$ State Key Laboratory of Genetic Resources and Evolution, Kunming Institute of Zoology, Kunming, Yunnan 650223, China

*Corresponding authors: gaojj@ynu.edu.cn, zhangyp@mail.kiz.ac.cn, hutian@lemon.plala.or.jp

Abstract. The genus Dichaetophora is currently comprised of 67 formally described species assigned into five species groups, i.e., agbo, tenuicauda, acutissima, sinensis and trilobita. In the present study, we challenged to delimit species from a huge amount of samples of Dichaetophora and allied taxa (the genus Mulgravea and the subgenus Dudaica of Drosophila) collected from a wide range of the Oriental and east Palearctic regions. We first sorted all specimens into morpho-species, which were tentatively classified into the species groups of Dichaetophora, Mulgravea and Dudaica based on the morphological diagnoses for these supraspecific taxa. Then, we selected representative specimen(s) for each morpho-species and subjected them to barcoding of $C O I$ (the cytochrome $c$ oxidase subunit I gene) sequences. The applied ABGD (automatic barcode gap discovery) algorithm estimated a total of 222 MOTUs (molecular operational taxonomic units). Although most of the morpho-species were recognized as individual MOTUs, some others were divided into multiple MOTUs or combined into a single MOTU, suggesting the existence of cryptic sibling species, subspecies or intraspecific genetic varieties. Out of the 222 MOTUs, 88 representing the supraspecific taxa of Dichaetophora, Mulgravea and Dudaica were selected, along with 33 species from major genera and subgenera of Drosophila in the tribe Drosophilini, as in-group (four species from the tribe Colocasiomyini as out-group) for phylogenetic reconstruction. We analyzed a dataset of concatenated nucleotide sequences of 12 nuclear gene markers by the maximum likelihood and Bayesian inference methods. As a result, the three focal taxa (i.e., Dichaetophora, Mulgravea and Dudaica) formed a clade, which we called the "pan-Dichaetophora". Within this large clade, the agbo, tenuicauda, sinensis and trilobita groups of Dichaetophora, Mulgravea and Dudaica were recovered as monophyletic groups, but Dichaetophora and its acutissima group were regarded as paraphyletic. In addition, two clusters were recognized among ungrouped MOTUs of Dichaetophora. Thus, the present study has uncovered some problems in the taxonomy of the pan-Dichaetophora. Solving such problems will be challenged in Part II of this serial work. 
Key words: ABGD analysis, COI barcoding, Dichaetophora, Drosophilidae, Dudaica, molecular phylogeny, MOTU, Mulgravea

\section{Introduction}

Duda (1940) established Dichaetophora as a subgenus in the genus Drosophila Fallén (Drosophilidae: Drosophilinae) with Drosophila aberrans Lamb, 1914 from the Seychelles as the type species. After that, a number of species were added to this subgenus from Africa (3 spp.; Burla, 1954; Graber, 1957) and East Asia (6 spp.; Lee, 1964; Okada, 1964, 1966, 1968; Kang et al., 1967). These East Asian species were, however, later transferred to the genus Nesiodrosophila Wheeler \& Takada (Okada, 1976, 1977, 1984a), which was established with Nesiodrosophila lindae Wheeler \& Takada, 1964 as the type species by Wheeler \& Takada (1964). Then, a large number of Nesiodrosophila species were found from the Old World: 14 spp. from the Oriental region (Lin \& Ting, 1971; Okada, 1984a, 1988; Gupta \& De, 1996), 3 spp. from the Palearctic region (Nishiharu, 1981; Toda, 1989), 15 spp. from the Australasian region (Bock, 1982; Okada, 1984a; Toda et al., 1987), and $1 \mathrm{sp}$. from the Afrotropical region (Okada, 1984a). In addition, another related taxonomic group, i.e., the Drosophila tenuicauda species group, was recognized within the subgenus Lordiphosa Basden of Drosophila (Toda, 1983; Okada, 1984b; Hu et al., 1999; Katoh et al., 2000): Hu \& Toda (2001) inferred the sister relationship between the tenuicauda group and Nesiodrosophila from a phylogenetic analysis based on 68 morphological characters. Grimaldi (1990) elevated Dichaetophora and Lordiphosa, along with the subgenera Hirtodrosophila Duda and Scaptodrosophila Duda of Drosophila, to the generic rank, based on the results of a family-wide cladistic analysis on 217 adult morphological characters.

Taking into account these possible relationships proposed in the previous studies, $\mathrm{Hu} \&$ Toda (2002) conducted a morphological cladistic analysis focusing on Dichaetophora, Nesiodrosophila and the Lordiphosa tenuicauda group. Based on the result that these three taxa formed a monophyletic group, all the species so far assigned to them were merged into the revised genus Dichaetophora: i.e., Nesiodrosophila was synonymized with Dichaetophora. And, within the revised Dichaetophora, three species groups were newly proposed: the agbo group comprised the four Afrotropical Dichaetophora species and all the species so far assigned to Nesiodrosophila, and the previous Lo. tenuicauda group was split into the tenuicauda and acutissima groups. Since then, two more species groups were added to Dichaetophora: the sinensis group comprised of four Chinese species (Hu \& Toda, 2005) and the trilobita group of six Oriental species (Yang et al., 2017).

The current genus Dichaetophora includes a total of 67 formally described species: 43 spp. of the agbo group, $10 \mathrm{spp}$. of the tenuicauda group, $4 \mathrm{spp}$. of the acutissima group, $4 \mathrm{spp}$. of the sinensis group, and $6 \mathrm{spp}$. of the trilobita group; $5 \mathrm{spp}$. distributed in the Palearctic region (East Asia), 6 spp. in the Palearctic (East Asia) and Oriental regions, 35 spp. in the Oriental region, $15 \mathrm{spp}$. in the Australasian region, $5 \mathrm{spp}$. in the Afrotropical region, and $1 \mathrm{sp}$. in the Palearctic (East Asia), Oriental and Australasian regions (DrosWLD-Species: https://bioinfo.museum.hokudai.ac.jp/db/index.php; TaxoDros: http://www.taxodros.uzh.ch/). Our intensive surveys of drosophilid faunas in the Oriental region during the past two decades uncovered very high species diversity of Dichaetophora from previously less explored microhabitats: an unexpectedly large number of putatively new species ( $c a$. 150) were recognized among specimens collected by net sweeping mostly from herbaceous stands or forest floor, occasionally from tree-trunks, flowers, fallen fruits and fungi, or by light traps. This finding of the great species diversity prompted us to a revisional work on the systematics 


\section{of Dichaetophora.}

The phylogeny of Dichaetophora has been less explored. Grimaldi (1990) included two species, Dr. aberrans and Nesiodrosophila rotundicornis (Okada, 1966), of the current Dichaetophora in his morphological cladistic analysis with an extensive taxon sampling of most genera and subgenera of the family Drosophilidae. However, the two species were placed in different lineages distant from each other in the resulting tree. When Hu \& Toda (2002) redefined the genus Dichaetophora, they suggested its relationships with the genera Jeannelopsis Séguy, Sphaerogastrella Duda, Mulgravea Bock and Liodrosophila Duda because an important diagnostic character "the oviscapt with apical ovisensillum robust and the largest, distinguishable from the others" for Dichaetophora is shared as a synapomorphy (ap. 213) of Grimaldi (1990) by these genera. This character is shared by the subgenus Dudaica Strand of Drosophila as well (Katoh et al., 2018). On the other hand, Hu \& Toda (2005) suggested the sister relationship between Hirtodrosophila and the monophyletic Dichaetophora comprised of the agbo, tenuicauda, acutissima and sinensis groups. The close relationship between Dichaetophora (the tenuicauda and acutissima groups) and Hirtodrosophila was suggested in molecular phylogenetic analyses by Katoh et al. (2000) and Russo et al. (2013) as well. Yassin (2013) constructed a family-wide Bayesian phylogenetic tree, based on a multi-locus (seven nuclear and one mitochondrial genes) dataset of DNA sequences from 190 species of 33 drosophilid genera, and inferred that Dichaetophora (the agbo, tenuicauda and acutissima groups) formed a cluster with the genera Hirtodrosophila, Mycodrosophila Oldenberg, Zygothrica Wiedemann, Dettopsomyia Lamb and Jeannelopsis. However, the statistical supports (Bootstrap, Bremer and/or Posterior Probability values) for these relationships were all low. Thus, the phylogenetic position of Dichaetophora and the relationship within this genus are still to be investigated, especially by means of molecular phylogenetic methods.

In the present study, we first try to delimit species of Dichaetophora and its relatives (the genus Mulgravea and the subgenus Dudaica of Drosophila) based on morphological and DNA barcode data, examining a huge amount of specimens of known and putatively new species of these focal taxa collected by our surveys for ten-odd years in the Oriental and East Asian regions. We then conduct a multi-locus molecular phylogenetic analysis with taxon sampling expanded from the three focal taxa to possibly allied genera/subgenera such as those mentioned above and species representing some major lineages of the subfamily Drosophilinae. The phylogeny to be reconstructed in this study will provide a framework for revising the taxonomy of Dichaetophora and allied taxa in a subsequent study of this serial work and baseline knowledge for future evolutionary studies on this speciose group of drosophilids adapted to particular microhabitats.

\section{Materials and methods}

\section{Fly samples and species delimitation}

We selected the genera Dichaetophora and Mulgravea and subgenus Dudaica of Drosophila as focal taxa from our samples of drosophilid flies collected from East and Southeast Asia (China, Japan, Vietnam, Myanmar, Malaysia and Indonesia) and Australia, mostly by net sweeping over herbaceous stands along forest edges or on the forest floor, sometimes by aspirating from flowers or by using light traps set in the tree canopy. Specimens were preserved in either ethanol ( $70 \%$ or $100 \%$ for morphological or molecular study, respectively) or Kahle's solution (to maintain the pigmentation of specimens for a long time in the 
laboratory; only for specimens collected from Myanmar and Australia) before this study.

The selected specimens were first sorted into morpho-species. A few representative specimens of each morpho-species were dissected by detaching the genitalia and/or some other body parts (e.g., head, mouthparts, legs, etc.) from the main body, and the detached organs were treated and examined in the same method as that described by Shi et al. (2019). And, putatively new species were tentatively classified into the five species groups of Dichaetophora, Mulgravea or Dudaica, based on their diagnostic, morphological characters (Hu \& Toda, 2002, 2005 for the agbo, tenuicauda, acutissima and sinensis groups of Dichaetophora; Yang et al., 2017 for the trilobita group of Dichaetophora; Bock, 1982 for Mulgravea; Katoh et al., 2018 for Dudaica). In this classification, many morpho-species completely conformed to the diagnosis of any group (i.e., having all the diagnostic characters), but some others only partially, and those of which morphology were inconsistent with any diagnosis were treated as ungrouped.

Some of the specimens thus identified to morpho-species were selected and subjected to DNA barcode sequencing, considering the total number, gender and geographical origins of the available specimens for each morpho-species (Table S1). We used the same methods as in Yang et al. (2017) for fly tissue sampling, DNA extraction (using TIANamp ${ }^{\circledR}$ Genome DNA Kit) and PCR [using TIANGEN ${ }^{\circledR}$ Taq DNA polymerase and Folmer et al.'s (1994) primer pair LCO1490/HCO2198]. The PCR products were subjected to sequencing in the TSINGKE Biological Technology (http://www.tsingke.net) with an ABI 3700 sequencer, with trace files edited subsequently in the SeqMan module of the DNAStar package version 7.1.0 (DNAStar Inc., Madison, WI).

Newly determined barcodes were aligned with $78 \mathrm{COI}$ sequences downloaded from GenBank (Table S1) in MEGA 7 (Kumar et al.. 2016) with the ClustalW method. A neighbor-joining (NJ) tree was then built with the resulting sequence alignment in MEGA 7 (options: model $=p$-distance, variance estimation method $=$ bootstrap method of 1,000 replicates, gaps treatment $=$ pair-wise deletion). Recognition of MOTUs (molecular operational taxonomic unit) was then conducted using the ABGD (automatic barcode gap discovery) algorithm (Puillandre et al., 2012) through the web interface (https://bioinfo.mnhn.fr/abi/public/abgd/abgdweb.html), with the "simple distance" (i.e., $p$-distance) option under default settings: $\operatorname{Pmin}=0.001, \operatorname{Pmax}=0.1$, Steps $=10, \mathrm{X}$ (a proxy for minimum gap width $)=1.5, \mathrm{Nb}$ bins $($ for distance distribution $)=20$.

\section{Taxon sampling for phylogenetic reconstruction}

We expanded the taxon sampling from the three focal taxa to some previously suggested relatives, such as Hirtodrosophila, Mycodrosophila, Zygothrica, Dettopsomyia and Liodrosophila, and also some major lineages, such as the subgenera Drosophila, Siphlodora Patterson \& Mainland and Sophophora Sturtevant of the genus Drosophila and Hawaiian drosophilids (Idiomyia Grimshaw and Scaptomyza Hardy), of the tribe Drosophilini Okada (sensu Yassin, 2013) as in-group taxa. For the three focal taxa, not all but a part of MOTUs recognized in the ABGD analysis of $\mathrm{COI}$ barcodes were applied to the phylogenetic reconstruction by selecting representatives from each genus, subgenus, species group and/or cluster recognized in the barcoding tree. In total, 88 MOTUs (including 25 known species) from the three focal taxa and 33 species from other in-group genera/subgenera were sampled for the phylogenetic analysis (Table S2). As out-group taxa, four species of Chymomyza Czerny, Colocasiomyia de Meijere, Impatiophila Fu \& Gao and Scaptodrosophila were selected from the tribe Colocasiomyini Okada (sensu Yassin, 2013) (Table S2). 


\section{Genetic markers and DNA sequencing}

We adopted 12 nuclear gene markers: the D7 region of the 28S rRNA locus (Friedrich \& Tautz, 1997) was used as a practicable marker, and 11 single-copy, orthologous, protein-coding gene (PCG) markers were set up by referring to the alignments of our unpublished transcriptome sequences of ten drosophilid species (three of Dichaetophora and seven of allied genera). The PCG markers were evaluated on the basis of sequence variation within the coding part of the target regions of the alignments.

We then designed PCR/sequencing primer pairs for each of these markers (Table 1) and chose optimal reaction condition for each pair by evaluating their performance with DNA samples of eight Dichaetophora species, acutissima (Okada, 1956), pseudocyanea (Hu \& Toda, 1999), tenuicauda (Okada, 1956), facilis (Lin \& Ting, 1971), ogasawarensis (Toda, 1987), lindae, neocirricauda (Gupta \& De, 1996) and trilobita Yang \& Gao, 2017, covering all the five species groups of this genus. Then, the target regions of the selected nuclear markers were amplified and sequenced for the in- and out-group taxa with the designed primer pairs (with the same procedures described in the DNA barcoding section, in the TSINGKE Biological Technology), and the resulting trace files were edited with SeqMan or MEGA7. The protein-coding part(s) of the newly collected sequences of each locus were aligned with some homologous sequences available from GenBank using the ClustalW method, and then concatenated for all loci, also in MEGA 7.

\section{Data partitioning and multi-locus phylogenetic reconstruction}

We used the program PartitionFinder 2 (Lanfear et al., 2016) to search optimal partitioning scheme for the alignment of the concatenated sequences and select the best fit nucleotide substation model for each suggested partition. The search was conducted with the greedy algorithm (Lanfere et al., 2012) under the BIC (Bayesian Information Criterion; Schwarz, 1978), with data blocks defined in light of gene locus and each codon position for the PCG sequences. The model was set as "models=all" for the ML, but "model=mrbayes" for the BI analyses. The ML tree was constructed using RAxML 1.0.1 (Kozlov et al., 2019), with node confidences evaluated through 1,000 non-parametric bootstrap replicates. The BI analysis was performed in MrBayes 3.2.7 (Ronquist et al., 2012) through two independent runs each including four MCMC chains, with chains sampled every 100 generations. The convergence of runs was evaluated in Tracer V1.6 (Rambaut et al., 2014) after discarding the initial 25\% samples as burn-in.

\section{Results}

\section{COI barcoding}

We determined COI sequences for 1,013 specimens of the three focal taxa: 1,004 of Dichaetophora, 5 of Mulgravea, and 4 of Dudaica (Table S1). The NJ barcode tree built with the alignment of these barcodes and 57 GenBank COI sequences (23 of the Di. trilobita group and 34 of Dudaica; Table S1) is shown in Fig. 1 (partially compressed) and Fig. S1 (original). In the ABGD analysis with all but one (\#00676 with only 212 nucleotide sites determined) of the $C O I$ sequences, a total of 177 to 311 MOTUs were recognized when the prior maximum intraspecific divergence $(P)$ was changed from 0.001000 to 0.021544 (Table 2). We selected $P$ $=0.004642$ as an optimal, where the numbers of MOTUs identified in the initial and recursive partitions were 222 and 226, respectively. We adopted the former estimate (222) as a hypothetical number of MOTUs. Among them, most of morpho-species (including all the 
studied, known species) were recognized as individual MOTUs, but some others were divided into multiple MOTUs or two morpho-species ( $D i$. sp.DLS3a and $D i$. sp.DLS3b) were combined into a single MOTU (Fig. 1, Fig. S1).

\section{Phylogenetic reconstruction}

DNA sequences of the 12 nuclear gene markers were newly determined for the 89 specimens (representing 88 MOTUs) selected from the three focal taxa (82 of Dichaetophora, three of Dudaica, and four of Mulgravea), 13 in-group and three out-group species (Table S2). The alignment of the data sets of these newly determined sequences and those from GenBank for 21 other species (20 in-group and 1 out-group spp.; Table S2) spans 4,571 nucleotide sites, among which 2,005 are variable and 1,710 are parsimony informative. The optimal partitioning strategy for the concatenated data set is shown in Table 3, together with the selected nucleotide substitution model for each partition.

The resulting ML tree rooted with the out-group is shown in Fig. 2. The topology of the BI tree was nearly identical to that of the ML tree, with only minor differences in branching order of the genus Microdrosophila Malloch, the subgenus Siphlodora of Drosophila and a few terminal MOTUs of the Di. agbo group (Fig. S2), which have no influence on our conclusions. The three focal taxa, Dichaetophora, Dudaica and Mulgravea, formed a clade with moderate $(\mathrm{BP}$ : bootstrap percentage $=67)$ and strong $(\mathrm{PP}$ : posterior probability $=1.00)$ support in the ML and Bayesian trees, respectively. This clade, hence called the "pan-Dichaetophora", was placed as sister to the moderately supported $(\mathrm{BP}=59, \mathrm{PP}=0.74)$ clade of the Zygothrica genus group, which included Hirtodrosophila, Zygothrica and Mycodrosophila in the present study, within the in-group (i.e., the tribe Drosophilini), although this sister relationship was not so strongly supported $(\mathrm{BP}=28, \mathrm{PP}=0.63)$.

Within the pan-Dichaetophora, six clades were recognized. Clade I $(\mathrm{BP}=91, \mathrm{PP}=1.00)$ was comprised of 41 MOTUs, all of which were morphologically classified into the Di. agbo group, including five described species, Di. ogasawarensis, Di. lindae, Di. delicata (Nishiharu, 1981), Di. surukella (Okada, 1965) and Di. sakagamii (Toda, 1989). Clade II (BP =96; PP = 1.00) consisted of the Di. acutissima group and the subgenus Dudaica. Within this clade, Dudaica was recovered as a monophyletic group $(\mathrm{BP}=100, \mathrm{PP}=1.00)$, but the acutissima group was regarded as paraphyletic with respect to Dudaica. The acutissima group was divided into two solid subclades $(\mathrm{BP}=100, \mathrm{PP}=1.00$ for both $)$ : one including Di. cyanea (Okada, 1988) and Di. pseudocyanea was placed as sister to Dudaica $(\mathrm{BP}=100, \mathrm{PP}=1.00)$, while the other including Di. acutissima and Di. harpophallata (Hu, Watabe \& Toda, 1999) as basal. Clade III (BP $=100, \mathrm{PP}=1.00)$ corresponded to the Di. tenuicauda group. Within this clade, the four known species, Di. tenuicauda, Di. emeishanensis (Hu \& Toda, 1999), Di. pseudotenuicauda (Toda, 1983) and Di. presuturalis (Hu \& Toda, 1999), sharing all the diagnostic characters for this species group, formed a solid cluster $(\mathrm{BP}=100, \mathrm{PP}=1.00)$, but the remaining MOTUs including $\mathrm{Di}$. facilis only partially conformed to the diagnosis. The ungrouped MOTU "Di. sp.8 Malaysia (Toda)" was placed as sister to Clade III, although the support for this relationship was weak $(\mathrm{BP}=35, \mathrm{PP}=0.52)$. Four other ungrouped MOTUs of Dichaetophora formed Clade IV with less support $(\mathrm{BP}=32, \mathrm{PP}=0.75)$. Clade V $(\mathrm{BP}=100$, $\mathrm{PP}=1.00)$ was comprised of two monophyletic, sister groups, i.e., the $D i$. sinensis group (BP $=95, \mathrm{PP}=1.00)$ and Di. trilobita group $(\mathrm{BP}=100, \mathrm{PP}=1.00)$. The classification of $\mathrm{Di}$. neocirricauda into the sinensis group was corroborated by its morphological congruence with the diagnosis of the sinensis group and molecular phylogenetic position, although this species is assigned to the agbo group in the current classification (DrosWLD-Species; TaxoDros). Clade VI $(\mathrm{BP}=53, \mathrm{PP}=1.00)$ was also comprised of two sister subclades: one corresponded 
to the genus Mulgravea $(\mathrm{BP}=92, \mathrm{PP}=1.00)$, and the other consisted of five ungrouped Dichaetophora MOTUs $(\mathrm{BP}=98, \mathrm{PP}=1.00)$. However, relationships among these six clades of the pan-Dichaetophora were less resolved in the present analysis.

\section{Discussion}

Our COI barcoding by the ABGD analysis estimated 222 MOTUs among a total of 1,070 specimens of the three taxa, the genera Dichaetophora and Mulgravea and the subgenus Dudaica of Drosophila, on which the present study focused. Most of these MOTUs corresponded to morpho-species first distinguished. The 34 known species included in the analysis were all recognized as individual MOTUs. Among them, Di. delicata, which had been synonymized, along with Di. pleurostriata (Singh \& Gupta, 1981), with Di. lindae by Okada (1984a), was included as a distinct MOTU (Figs 1 and 2, Fig. S1): thus, its status as a valid species was strongly suggested by both morphological and molecular evidence. The status for these three species once synonymized should be reconsidered in connection with other related MOTUs inferred from the present study. On the other hand, some morpho-species were divided into multiple MOTUs: for example, "Di. sp.G2 (Toda)" into sp.G2a and sp.G2b MOTUs, "Di. sp.G3 (Toda)" into sp.G3a and sp.G3b MOTUs, and "Di. sp.WTS8 (Gao)” into sp.WTS8a-d MOTUs (Fig. 1, Fig. S1). These MOTUs may include cryptic, sibling species, subspecies, or intraspecific genetic varieties. On the contrary, two morpho-species, "Di. sp.DLS3a (Gao)" and "Di. sp.DLS3b (Gao)" which are distinctly different from each other in the morphology of aedeagus and aedeagal apodeme (Fig. 1H), were combined into a single MOTU (Fig. 1, Fig. S1). To determine boundaries of valid species, we need to re-examine the morphology of suggested MOTUs in more detail and to incorporate data from biogeography and ecology into the species delimitation. Leaving such a work for the final delimitation to Part II of this serial study, we tentatively classified the suggested MOTUs (222 in total) into supraspecific categories (genus, subgenus and/or species group) under the current classification framework of the focal taxa: 128 of the agbo group, 39 of the tenuicauda group, 18 of the acutissima group, 6 of the sinensis group, 6 of the trilobita group, and 12 ungrouped species of Dichaetophora, 5 of Mulgravea, and 8 of Dudaica (Table 4).

Of these MOTUs, 88 (41 of the agbo group, 13 of the tenuicauda group, 9 of the acutissima group, 5 of the sinensis group, 3 of the trilobita group, and 10 ungrouped species of Dichaetophora, 4 of Mulgravea, and 3 of Dudaica) were selected for the phylogenetic reconstruction based on the 12 nuclear gene markers. In the resulting tree, the three focal taxa (Dichaetophora, Mulgravea and Dudaica) formed a clade, which we provisionally called the pan-Dichaetophora. Within this large clade, Mulgravea and Dudaica were recovered as monophyletic groups, but Dichaetophora was paraphyletic in respect to the former two taxa. Furthermore, four of the five species groups of Dichaetophora were recovered as strongly supported monophyletic groups, but the acutissima group was paraphyletic in respect to Dudaica. Of the four monophyletic species groups, the sinensis and trilobita groups were sister to each other. In addition, two solid clades were recognized among the ungrouped MOTUs of Dichaetophora. One was comprised of five MOTUs of Part 2 and sister to Mulgravea, and the other was of three MOTUs tentatively classified into Part 1 . Thus, the present study has uncovered some problems in the taxonomy of the pan-Dichaetophora. For instance, (i) are Mulgravea and Dudaica to be synonymized with Dichaetophora, or is the pan-Dichaetophora to be divided into a few genera; (ii) are the sinensis and trilobita groups to be combined into a species group; and (iii) are any species subgroups and/or complexes to 
be established within species groups? To solve these problems, it would be effective to incorporate all known and putatively new species (i.e., MOTUs inferred from the present study) into a grafting phylogenetic analysis with morphological characters (e.g. Fu et al., 2016). Based on the topology of resulting tree and the character mapping on it, the clade-based classification system will be established for the pan-Dichaetophora: each supraspecific taxon is to be monophyletic and defined by synapomorphies as the diagnosis, and all component species are explicitly assigned in the hierarchical system of such supraspecific taxa. This will be challenged in Part II of this serial work.

\section{Acknowledgements}

We thank Administrations of the Xishuangbanna, Gaoligongshan, Jianfengling and Taibaishan National Nature Reserves, the Xishuangbanna Tropical Botanical Garden, CAS, the Fushan Botanical Garden, and the Forestry Bureau of Xizang Autonomous Region for administrative supports during field survey in each Garden/Reserve. We also thank Dr. Shun-Chern Tsaur, Dr. Chau-Ti Ting, Dr. Fu-Guo Robert Liu, Mr. Zhi-Wei Chang, Dr. Hong-Wei Chen, Dr. Xi-Peng Chen, Mr. Zhao Fu, Ms. Nan-Nan Li for their help in field works in China; Dr. Shin-ichi Tanabe, Dr. Maklarin B. Lakim, Dr. Rimi Repin and Dr. Maryati Bte Mohamed for their help in field works in Sabah, Malaysia, under research permissions (UPE:40/200/19 SJ. 732 and UPE: 40/200/19 SJ.1194 and 1195) of Economic Planning Unit of Malaysian Government; Dr. Lucy Chong, Dr. Kohei T. Takano, Dr. Takao Itioka and Dr. Tohru Nakashizuka for their help with field work in the Lambir Hills National Park, Sarawak, Malaysia, in accordance with the Memorandums of Understanding signed between the Sarawak Forestry Corporation (SFC, Kuching, Malaysia) and the Japan Research Consortium for Tropical Forests in Sarawak (JRCTS, Sendai, Japan) in November 2005, and under Sarawak Forestry Department Permission to Conduct Research on Biological Resources - Permit No.

NCCD.907.4.4(J|d.7)-109 and Park Permit No. 50/2012; Dr. Sri Hartini and other staff members of Zoology Division, Research Center for Biology-LIPI, Indonesia, for their help with field work in Java and Sumatra under research permissions 5816/SU/KS/2004 and 6967/SU/KS/2004; Dr. Bui Tuan Viet for his help with field work in Vietnam; Prof. Masayoshi Watada for his help in field works in Ehime, Japan; and Dr. Artyom Kopp and Dr. Toru Katoh for discussion about phylogenetic reconstruction. This work was supported by NSFC (Nos 31160429, 32060112 and 31760617), the fund of the Ministry of Science and Technology of China (Nos 2011FY120200 and 2012FY110800), JSPS KAKENHI Grants Numbers 15255006, 21570085, 23405004, 24370033 and 25257416, Creative Basic Research 09NP1501 and the 21st Century Center of Excellence Program (E-01) of the Ministry of Education, Culture, Sports, Science and Technology, Japan.

\section{References}

Bock IR. 1982. Drosophilidae of Australia V. Remaining genera and synopsis (Insecta: Diptera). Australian Journal of Zoology, Supplementary Series, 30(89):1-164.

Burla H. 1954. Zur Kenntnis der Drosophiliden der Elfenbeinküste (Französisch West-Afrika). Revue Suisse Zoologie, 61(Suppl.):1-218.

Duda O. 1926. Fauna sumatrensis: Drosophilidae (Diptera). Supplementa Entomologica, 14:42-116.

Duda O. 1940. Revision der afrikanischen Drosophiliden (Diptera). II. Annales 
Historico-Naturales Musei Nationalis Hungarici, 33:19-53.

Folmer O, Black M, Hoeh W, Lutz R, Vrijenhoek R. 1994. DNA primers for amplification of mitochondrial cytochrome $c$ oxidase subunit I for diverse metazoan invertebrates. Molecular Marine Biology and Biotechnology, 3(5):294-299.

Fu Z, Toda MJ, Li NN, Zhang YP, Gao JJ. 2016. A new genus of anthophilous drosophilids, Impatiophila (Diptera, Drosophilidae): morphology, DNA barcoding and molecular phylogeny, with descriptions of thirty-nine new species. Zootaxa, 4120 (1):1-100. doi:10.11646/zootaxa.4120.1.1

Friedrich M, Tautz D. 1997. Evolution and phylogeny of the Diptera: a molecular phylogenetic analysis using 28S rDNA sequences. Systematic Biology, 46(4):674-698; doi:10.1093/sysbio/46.4.674

Graber H. 1957. Afrikanische Drosophiliden als Blütenbesucher. Zoologische Jahrbucher, 85(Syst.): 305-316.

Grimaldi DA. 1990. A phylogenetic, revised classification of genera in the Drosophilidae (Diptera). Bulletin of the American Museum of Nattural History, 197:1-139.

Gupta JP, De A. 1996. Records of Drosophilidae with description of two new species from Bhutan (Insecta: Diptera). Entomon, 21(2):177-186.

Hu YG, Toda MJ, Watabe HA. 1999. A revision of the Lordiphosa tenuicauda species group, with descriptions of eight new species from China (Diptera: Drosophilidae) Entomological Science, 2(1):105-199.

Hu YG, Toda MJ. 2001. Polyphyly of Lordiphosa and its relationships in Drosophilinae (Diptera: Drosophilidae). Systematic Entomology, 26:15-31. doi:10.1046/j.1365-3113.2001.00135.x

Hu YG, Toda MJ. 2002. Cladistic analysis of the genus Dichaetophora Duda (Diptera: Drosophilidae) and a revised classification. Insect Systematics and Evolution, 33:91-102. doi:10.1163/187631202X00064

Hu YG, Toda MJ. 2005. A new species group in the genus Dichaetophora Duda (Diptera: Drosophilidae) based on a phylogenetic analysis, with descriptions of four new species from China. Zoological Science, 22:1265-1276. doi:10.2108/zsj.22.1265

Kang YS, Lee TJ, Bahng KW. 1967. On Drosophila quelpartiensis sp. nov. with supplementary notes on the female of Drosophila pseudonokogiri Kang, Lee and Bahng. Korean Journal of Zoology, 10:71-72.

Katoh T, Tamura K, Aotsuka T. 2000. Phylogenetic position of the subgenus Lordiphosa of the genus Drosophila (Diptera: Drosophilidae) inferred from alcohol dehydrogenase (Adh) gene sequences. Journal of Molecular Evolution, 51(2):122-130. doi:10.1007/s002390010072

Katoh TK, Zhang G, Toda MJ, Suwito A, Gao JJ. 2018. A revision of the subgenus Dudaica Strand of the genus Drosophila Fallén, with descriptions of six new species (Diptera, Drosophilidae) ZooKeys, 781:19-50; doi:10.3897/zookeys.781.27354

Kozlov AM, Darriba D, Flouri T, Morel B, Stamatakis A. 2019. RAxML-NG: a fast, scalable and user-friendly tool for maximum likelihood phylogenetic inference. Bioinformatics, 35(21):4453-4455; doi:10.1093/bioinformatics/btz305

Kumar S, Stecher G, Tamura K. 2016. MEGA7: Molecular Evolutionary Genetics Analysis version 7.0 for bigger datasets. Molecular Biology and Evolution, 33(7):1870-1874; 
doi:10.1093/molbev/msw054

Lanfear R, Calcott B, Ho SYW, Guindon S. 2012. Partitionfinder: combined selection of partitioning schemes and substitution models for phylogenetic analyses. Molecular Biology and Evolution, 29(6):1695-1701; doi:10.1093/molbev/mss020

Lanfear R, Frandsen PB, Wright AM, Senfeld T, Calcott B. 2016. PartitionFinder 2: new methods for selecting partitioned models of evolution for molecular and morphological phylogenetic analyses. Molecular Biology and Evoluton, 34(3):772-773; doi:10.1093/molbev/msw260

Lee TJ. 1964. Taxonomy, and geographical distribution of Drosophilidae (Diptera) in Korea. The Chungang University Theses Collection, 9:425-459.

Lin FJ, Ting JI. 1971. Several additions to the fauna of Taiwan Drosophilidae (Diptera). Bulletin of the Institute of Zoology, Academia Sinica, 10(1):17-35.

Nishiharu S. 1981. Three new species of the genus Nesiodrosophila from Japan with a note on N. surukella Okada. Kontyû, 49(1):19-26.

Okada T. 1964. Drosophilidae (Diptera) of southeast Asia collected by the Thai-Japanese expedition 1961-62. In: Kira T, Umesao T. Nature and Life in Southeast Asia. Kyoto: Fauna and Flora Research Society, 3:439-466.

Okada T. 1966. Diptera from Nepal. Cryptochaetidae. Diastatidae \& Drosophilidae. Bulletin of the British Museum (Natural History) Entomology Supplement 6:1-129.

Okada T. 1968. Addition to the fauna of the family Drosophilidae of Japan and adjacent countries (Diptera). II. Genera Paramycodrosophila, Mycodrosophila, Liodrosophila, and Drosophila, including a few subgenus Psilodorha. Kontyû 36(4):324-340.

Okada T. 1976. New distribution records of the drosophilids in Oriental Region. Makunagi (Acta Dipterologica), 8, 1-9. (In Japanese)

Okada T. 1977. Family Drosophilidae. In: Hardy DE, Delfinado MA. Catalog of the Diptera of the Oriental Region, Vol. III. Suborder Cyclorrhapha (excluding Division Aschiza), Honolulu: The University Press of Hawaii, Honolulu, 342-387.

Okada T. 1984a. Descriptions of new species of the genus Nesiodrosophila Wheeler et Takada (Diptera, Drosophilidae), with taximetrical analyses. Kontyû, 52(1):21-36.

Okada T. 1984b. New or little known species of Drosophila (Lordiphosa) with taximetrical analyses (Diptera, Drosophilidae), Kontyû, 52(4):565-575.

Okada T. 1988. Family Drosophilidae (Diptera) from the Lund University Ceylon Expedition in 1962 and Borneo collections in 1978-1979. Entomologica Scandinavica Supplement, 30:111-151.

Puillandre N, Lambert A, Brouillet S, Achaz G. 2011. ABGD, Automatic barcode gap discovery for primary species delimitation. Molecular Ecology, 21(8):1864-1877. doi:10.1111/j.1365-294X.2011.05239.x

Rambaut A, Suchard MA, Xie D, Drummond AJ. 2014. Tracer v1.6. Available from: http://tree.bio.ed.ac.uk/software/tracer

Ronquist F, Teslenko M, van der Mark P, Ayres DL, Darling A, Höhna S, et al. 2012. MrBayes 3.2: Efficient Bayesian phylogenetic inference and model choice across a large model space. Systematic Biology, 61(3):539-542; doi:10.1093/sysbio/sys029

Russo CA, Mello B, Frazão A, Voloch CM. 2013. Phylogenetic analysis and a time tree for a 
large drosophilid data set (Diptera: Drosophilidae). Zoological Journal of the Linnean Society, 169(4):765-775; doi:10.1111/zoj.12062

Schwarz G. 1978. Estimating the dimension of a model. Annals of Statistics, 6(2):461-464; doi:10.1214/aos/1176344136

Shi T, Toda MJ, Takano KT, Yafuso M, Suwito A, Wong SY, et al. 2019. A review of taxonomy and flower-breeding ecology of the Colocasiomyia toshiokai species group (Diptera: Drosophilidae), with description of a new species from Indonesia. European Journal of Entomology, 116:341-361; doi: 10.14411/eje.2019.037

Toda MJ. 1983. Two species of the subgenus Lordiphosa Basden of the genus Drosophila (Diptera, Drosophilidae) from Japan. Kontŷ̂, 51(3):468-473.

Toda MJ. 1989. Three new and one newly recorded species of Drosophilidae (Diptera) from Japan. Japanese Journal of Entomology, 57(2):375-382.

Toda MJ, Riihimaa A, Fuyama Y. 1987. Additional notes on drosophilid flies (Diptera, Drosophilidae) in the Bonin Islands, with descriptions of two new species. Konty $\hat{u}$, 55(2):140-258.

Wheeler MR, Takada H. 1964. Insects of Micronesia Diptera: Drosophilidae. Bernice P. Bishop Museum Special Publication, 14(6):164-242.

Yang JH, Toda MJ, Suwito A, Hashim R, Gao JJ. 2017. A new species group in the genus Dichaetophora, with descriptions of six new species from the Oriental region (Diptera, Drosophilidae). ZooKeys, 665:121-146; doi:10.3897/zookeys.665.11609

Yassin A. 2013. Phylogenetic classification of the Drosophilidae Rondani (Diptera): the role of morphology in the postgenomic era. Systematic Entomology, 38(2):349-364; doi:10.1111/j.1365-3113.2012.00665.x 
Table 1. PCR/sequencing primer pairs designed for nuclear markers in the present study.

\begin{tabular}{|c|c|c|}
\hline Gene locus & Primer names and sequence $\left(3^{\prime}-5^{\prime}\right)$ & $\begin{array}{l}\text { Annealing } \\
\text { temperature }\end{array}$ \\
\hline $\begin{array}{l}\text { Adenylosuccinate synthetase } \\
(A d S S)\end{array}$ & $\begin{array}{l}\text { AdSS-f: TGGGYACCACCAAAAAGGG } \\
\text { AdSS-r: GGATACGTGCCAAARTCAATG }\end{array}$ & 50 \\
\hline $\begin{array}{l}\text { ATP synthase, subunit B } \\
(\text { ATPsynB) }\end{array}$ & $\begin{array}{l}\text { ATPsynB-f: GAGGARTGGTTCCAGTTYTT } \\
\text { ATPsynB-r: GCAATRTTYTCCTTCTTGGC }\end{array}$ & 50 \\
\hline Burgundy (bur) & $\begin{array}{l}\text { bur-f: GGCATYGATTTRATAGTGC } \\
\text { bur-r: GTTTCCGCRTTCKTGCTGAC }\end{array}$ & 48 \\
\hline Cell death protein 6 (ced-6) & $\begin{array}{l}\text { ced-6-f: GARACGGGCACACAGGAGAA } \\
\text { ced-6-r: CCTGTAGGCCAAATCAAARG }\end{array}$ & 53 \\
\hline $\begin{array}{l}\text { Eukaryotic translation } \\
\text { initiation factor } 3, \text { subunit } C \\
(\text { eIF3-S8) }\end{array}$ & $\begin{array}{l}\text { eIF3-S8-f: GYCAAATGCCATTCCAYATG } \\
\text { eIF3-S8-r: AAGTTGCCCTGCTTCATGTC }\end{array}$ & 52 \\
\hline $\begin{array}{l}\text { Protein disulfide isomerase } \\
(P d i)\end{array}$ & $\begin{array}{l}\text { Pdi-f: GATTGGGACAARCARCCCGTC } \\
\text { Pdi-r: TTACAACTCRTCCTTCTTRGGC }\end{array}$ & 50 \\
\hline $\begin{array}{l}\text { Phosphoglucose isomerase } \\
(\text { Pgi) }\end{array}$ & $\begin{array}{l}\text { Pgi-f: GAAGGAGTTTACCAAYAAGG } \\
\text { Pgi-r: CCWACCCAATCCCARAAACC }\end{array}$ & 46 \\
\hline Ribosomal protein L3 (RpL3) & $\begin{array}{l}\text { RpL3-f: AAAAGAAGGCGCACATCATG } \\
\text { RpL3-r: GATCTTCTTGTTGATCTCGG }\end{array}$ & 50 \\
\hline $\begin{array}{l}\text { Ribosomal protein } S 17 \\
(\mathrm{RpS} 17)\end{array}$ & $\begin{array}{l}\text { RpS17-f: TCGCGTCAGAACCAAGACWG } \\
\text { RpS17-r: CCTCYTCCTGCAGCTTAATGG }\end{array}$ & 53 \\
\hline Seven in absentia (sina) & $\begin{array}{l}\text { sina-f: AGTGCTGGGAACACATCMTC } \\
\text { sina-r: AACGCCCTCGTGTATGGAAC }\end{array}$ & 55 \\
\hline $\begin{array}{l}\text { Vacuolar } H^{+}-A T P a \text { ase SFD } \\
\text { subunit }(\text { VhaSFD) }\end{array}$ & $\begin{array}{l}\text { VhaSFD-f: TAYATGCARTCGCAAATGAT } \\
\text { VhaSFD-r: TRAGGAACTGCAAGTAGAAG }\end{array}$ & 44 \\
\hline
\end{tabular}


bioRxiv preprint doi: https://doi.org/10.1101/2021.05.28.446102; this version posted July 19, 2021. The copyright holder for this preprint (which

was not certified by peer review) is the author/funder, who has granted bioRxiv a license to display the preprint in perpetuity. It is made available under aCC-BY-NC-ND 4.0 International license.

Table 2. The numbers of MOTUs estimated at various values of the prior intraspecific divergence $(P)$ in the ABGD analysis.

\begin{tabular}{ccc}
\hline \multirow{2}{*}{ Prior intraspecific divergence $(P)$} & \multicolumn{2}{c}{ Number of MOTUs } \\
\cline { 2 - 3 } & Initial partition & Recursive partition \\
\hline 0.001000 & 309 & 311 \\
0.001668 & 309 & 310 \\
0.002783 & 309 & 310 \\
0.004642 & 222 & 226 \\
0.007743 & 222 & 224 \\
0.012915 & 173 & 179 \\
0.021544 & 173 & 177 \\
\hline
\end{tabular}


Table 3. Optimal partitioning strategies and substitution models selected for the concatenated DNA sequences of 12 nuclear gene markers in phylogenetic reconstruction by the Bayesian inference and the maximum likelihood methods.

\begin{tabular}{|c|c|c|c|c|}
\hline Method & Partition \# & Constituent block $(\mathrm{s})^{\mathrm{a}}$ & No. of sites & Selected model ${ }^{\mathrm{b}}$ \\
\hline \multirow[t]{13}{*}{ Bayesian inference } & 1 & AdSS_CP ${ }_{3}, A T P s y n B \_\mathrm{CP}_{3}, P d i \_\mathrm{CP}_{3}$, VhaSFD_CP $\mathrm{CP}_{3}$ & 436 & GTR+I+G \\
\hline & 2 & AdSS_CP 1 , bur_CP $1, P g i \_\mathrm{CP}_{1}$, VhaSFD_CP 1 & 416 & $\mathrm{SYM}+\mathrm{I}+\mathrm{G}$ \\
\hline & 3 & AdSS_CP $2, R p L 3 \_\mathrm{CP}_{1}$ & 191 & $\mathrm{~K} 80+\mathrm{I}+\mathrm{G}$ \\
\hline & 4 & ATPsynB_CP ${ }_{1}$, ced-6_CP $1, P d i \_\mathrm{CP}_{1}$ & 344 & $\mathrm{GTR}+\mathrm{I}+\mathrm{G}$ \\
\hline & 5 & ATPsynB_CP 2, ced-6_CP 2 & 219 & $\mathrm{SYM}+\mathrm{I}+\mathrm{G}$ \\
\hline & 6 & bur_ $\mathrm{CP}_{3}$, ced-6_CP $\mathrm{CP}_{3}$ & 200 & $\mathrm{SYM}+\mathrm{I}+\mathrm{G}$ \\
\hline & 7 & bur_CP $2, e I F 3-S 8 \_\mathrm{CP}_{2}, R p L 3 \_\mathrm{CP}_{2}, R p S 17 \_\mathrm{CP}_{2}$ & 436 & $\mathrm{~F} 81+\mathrm{I}+\mathrm{G}$ \\
\hline & 8 & eIF3-S8_CP $1, R p S 17 \_\mathrm{CP}_{1}$, sina_ $\mathrm{CP}_{1}$ & 491 & $\mathrm{SYM}+\mathrm{I}+\mathrm{G}$ \\
\hline & 9 & eIF3-S8_CP 3 ,Pgi_CP 3 & 327 & $\mathrm{GTR}+\mathrm{I}+\mathrm{G}$ \\
\hline & 10 & Pdi_CP $\mathrm{CP}_{2}, P g i \_\mathrm{CP}_{2}$, VhaSFD_CP 2 & 368 & $\mathrm{GTR}+\mathrm{I}+\mathrm{G}$ \\
\hline & 11 & $R p L 3 \_\mathrm{CP}_{3}, R p S 17 \_\mathrm{CP}_{3}$, sina_ $\mathrm{CP}_{3}$ & 388 & $\mathrm{GTR}+\mathrm{I}+\mathrm{G}$ \\
\hline & 12 & sina_ $\mathrm{CP}_{2}$ & 230 & JC69+I \\
\hline & 13 & $28 S$ rRNA & 525 & $\mathrm{GTR}+\mathrm{I}+\mathrm{G}$ \\
\hline \multirow[t]{13}{*}{ Maximum likelihood } & 1 & AdSS_CP $3, A T P s y n B \_\mathrm{CP}_{3}, P d i \_\mathrm{CP}_{3}$, VhaSFD_CP $\mathrm{CP}_{3}$ & 436 & $\mathrm{GTR}+\mathrm{I}+\mathrm{G}$ \\
\hline & 2 & AdSS_CP 1, bur_CP $1, P g i \_\mathrm{CP}_{1}$ & 301 & $\mathrm{SYM}+\mathrm{I}+\mathrm{G}$ \\
\hline & 3 & AdSS_CP $2, P d i \_\mathrm{CP}_{1}, R p L 3 \_\mathrm{CP}_{1}$ & 316 & $\operatorname{TrNef}+\mathrm{I}+\mathrm{G}$ \\
\hline & 4 & $A T P s y n B \_\mathrm{CP}_{1}$, VhaSFD_CP 1 & 216 & $\mathrm{TIM} 1+\mathrm{I}+\mathrm{G}$ \\
\hline & 5 & ATPsynB_CP 2 ,ced-6_CP 2 & 219 & $\mathrm{SYM}+\mathrm{I}+\mathrm{G}$ \\
\hline & 6 & bur_ $\mathrm{CP}_{3}$, ced-6_CP $\mathrm{CP}_{3}$, & 200 & $\mathrm{SYM}+\mathrm{I}+\mathrm{G}$ \\
\hline & 7 & bur_CP $2, e I F 3-S 8 \_\mathrm{CP}_{1}, R p L 3 \_\mathrm{CP}_{2}, R p S 17 \_\mathrm{CP}_{1}$, sina_CP 1 & 667 & $\operatorname{TrNef}+\mathrm{I}+\mathrm{G}$ \\
\hline & 8 & ced-6_CP $\mathrm{CP}_{1}$ & 118 & $\operatorname{TrN}+\mathrm{I}+\mathrm{G}$ \\
\hline & 9 & eIF3-S8_CP $2, P d i \_\mathrm{CP}_{2}, P g i \_\mathrm{CP}_{2}$, VhaSFD_CP 2 & 576 & $\mathrm{TVM}+\mathrm{I}+\mathrm{G}$ \\
\hline & 10 & eIF3-S8_CP $3, P g i \_\mathrm{CP}_{3}$ & 327 & $\mathrm{GTR}+\mathrm{I}+\mathrm{G}$ \\
\hline & 11 & $R p L 3 \_\mathrm{CP}_{3}, R p S 17 \_\mathrm{CP}_{3}$, sina_ $\mathrm{CP}_{3}$ & 388 & $\mathrm{GTR}+\mathrm{I}+\mathrm{G}$ \\
\hline & 12 & RpS17_CP 2, sina_ $\mathrm{CP}_{2}$ & 291 & JC69+I \\
\hline & 13 & $28 S$ rRNA & 525 & $\mathrm{TVM}+\mathrm{I}+\mathrm{G}$ \\
\hline
\end{tabular}

\footnotetext{
a Shown in the form of "gene locus_codon position"; codon position specified with subscript.
} 
${ }^{\mathrm{b}}$ Model: F81, Felsenstein 1981 model; sGTR, General time reversible; K80, Kimura 2-parameter model; SYM, Symmetrical model; JC69, Jukes-Cantor 1969 model; TrNef, Tamura-Nei equal base frequency model; TIM1, Transition model; TVM, Transition model; TrN,

Tamura-Nei model. Indices: I, proportion of invariable sites; G, gamma-distributed rate variation. 
Table 4. The numbers of known species and MOTUs (molecular operational taxonomic unit) estimated by the ABGD analysis for COI barcoding, separately enumerated for each species group and ungrouped category of Dichaetophora, the genus Mulgravea, and the subgenus Dudaica of Drosophila.

\begin{tabular}{|c|c|c|c|c|}
\hline \multirow{2}{*}{ Genus (subgenus) and species group } & \multirow{2}{*}{$\begin{array}{c}\text { Number of } \\
\text { known species a }\end{array}$} & \multicolumn{3}{|c|}{ MOTUs $^{\mathrm{b}}$ estimated by ABGD / subjected to phylogenetic reconstruction } \\
\hline & & Known species & Newly recognized & Total \\
\hline Dichaetophora agbo group & 43 & $6 / 5$ & $122 / 36$ & $128 / 41$ \\
\hline Dichaetophora tenuicauda group & 10 & $6 / 5$ & $33 / 8$ & $39 / 13$ \\
\hline Dichaetophora acutissima group & 4 & $4 / 4$ & $14 / 5$ & $18 / 9$ \\
\hline Dichaetophora sinensis group & 4 & $2 / 2$ & $4 / 3$ & $6 / 5$ \\
\hline Dichaetophora trilobita group & 6 & $6 / 3$ & $0 / 0$ & $6 / 3$ \\
\hline Ungrouped Dichaetophora & 0 & $0 / 0$ & $12 / 10$ & $12 / 10$ \\
\hline Mulgravea & 14 & $3 / 3$ & $2 / 1$ & $5 / 4$ \\
\hline Drosophila (Dudaica) & 8 & $7 / 3$ & $1 / 0$ & $8 / 3$ \\
\hline Total & 89 & $34 / 25$ & $188 / 63$ & 222/88 \\
\hline
\end{tabular}

${ }^{a}$ Based on the current classification of DrosWLD-Species and TaxoDros.

${ }^{\mathrm{b}}$ Classified into supraspecific taxa (genus, subgenus and/or species group), based on the morphological diagnosis for each taxon. 


\section{Figure legends}

Figure 1. Neighbor-joining tree (within-MOTU branches compressed) built with 1,070 COI sequences of the genera Dichaetophora and Mulgravea and the subgenus Dudaica of Drosophila. The skeleton of the tree is shown in panel A, and sub-trees shown individually in B-J. Voucher specimen number (or GenBank accession number) is shown for each sequence. MOTUs inferred from the ABGD analysis is shown, with indication of supraspecific classification in different colors: the agbo (green), acutissima (brown), tenuicauda (blue), trilobita (pink), sinensis (red) species groups and ungrouped species (gray) of Dichaetophora, Mulgravea (purple), and Dudaica (light brown). MOTUs only partially concordant with the diagnosis are asterisked and those having female specimens only are indicated with dagger $(\dagger)$, and both are shown in pale color. MOTUs subjected to the phylogenetic reconstruction are shown with thick branch(es). Bootstrap percentages more than $50 \%$ are shown beside nodes.

Figure 2. Maximum likelihood tree constructed for the genera Dichaetophora and Mulgravea and the subgenus Dudaica of Drosophila as the main target (shaded yellow) in the tribe Drosophilini (in-group), based on DNA sequences of 12 nuclear gene markers. The tree is rooted by out-group rooting (the tribe Colocasiomyini as the out-group). For the three focal taxa, a total of 88 MOTUs (molecular operational taxonomic units) were selected from those inferred from the ABGD analysis for COI barcoding (Fig. 1). Supraspecific classification of them based on the morphological diagnosis for each taxon is shown in different colors: the agbo (green), acutissima (brown), tenuicauda (blue), trilobita (pink), sinensis (red) species groups and ungrouped species (gray) of Dichaetophora, Mulgravea (purple), and Dudaica (light brown). MOTUs only partially concordant with the diagnosis are asterisked and shown in pale color. Support value of ML bootstrap percentage/Bayesian posterior probability (“-” indicating the corresponding branch not realized in the Bayesian inference) is shown for every internal branch. The voucher numbers of specimens used for DNA sequencing in the present study are shown at corresponding terminal branches.

\section{Supplementary information}

Table S1. Specimens of the genera Dichaetophora and Mulgravea and the subgenus Dudaica of Drosophila used for COI barcoding.

Table S2. Species/MOTUs and DNA sequences (newly determined ones: MT662140-MT663148) employed in the phylogenetic reconstruction. A hyphen (“-”) is used to indicate a case of missing data.

Figure S1. Neighbor-joining tree (original) built with 1,070 COI sequences of the genera Dichaetophora and Mulgravea and the subgenus Dudaica of Drosophila. Voucher specimen number (or GenBank accession number) is shown for each sequence. MOTUs inferred from the ABGD analysis is shown, with indication of supraspecific classification in different colors: the agbo (green), acutissima (brown), tenuicauda (blue), trilobita (pink), sinensis (red) species groups and ungrouped species (gray) of Dichaetophora, Mulgravea (purple), and Dudaica (light brown). MOTUs only partially concordant with the diagnosis are asterisked and those having female specimens only are indicated by dagger $(\dagger)$, and both are shown in pale color. MOTUs (voucher or Genbank accession numbers of the selected specimens underlined) subjected to the phylogenetic reconstruction are shown with thick branch(es). Bootstrap percentages more than $50 \%$ are shown beside nodes.

Figure S2. Bayesian Inference tree constructed based on DNA sequences of 12 nuclear gene 
bioRxiv preprint doi: https://doi.org/10.1101/2021.05.28.446102; this version posted July 19, 2021. The copyright holder for this preprint (which

was not certified by peer review) is the author/funder, who has granted bioRxiv a license to display the preprint in perpetuity. It is made available under aCC-BY-NC-ND 4.0 International license.

markers. Support value of Bayesian posterior probability is shown for every internal branch. The dashed lines indicate branches resulting only from the ML analysis. See the legend of Fig. 2 for more explanation. 

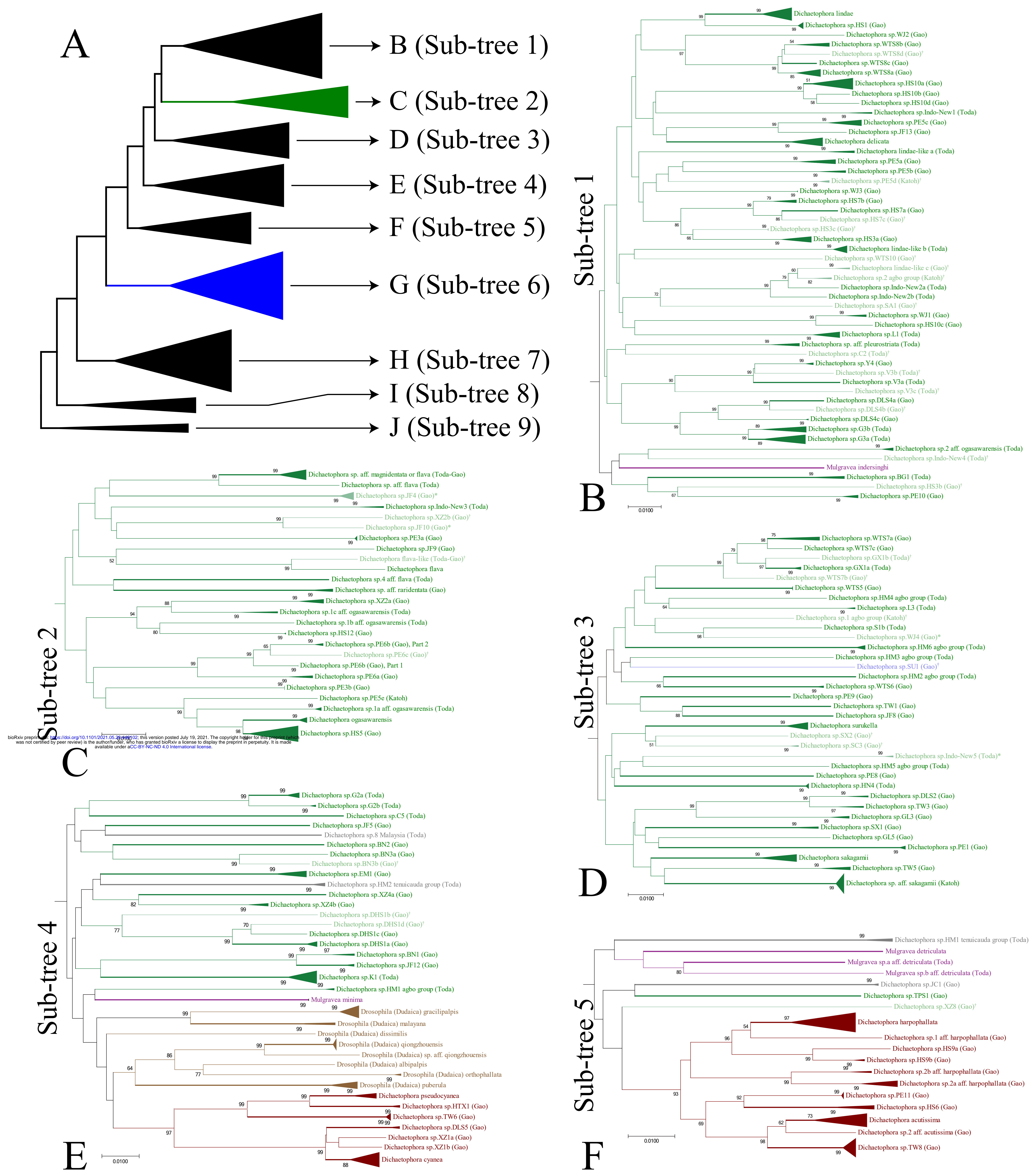

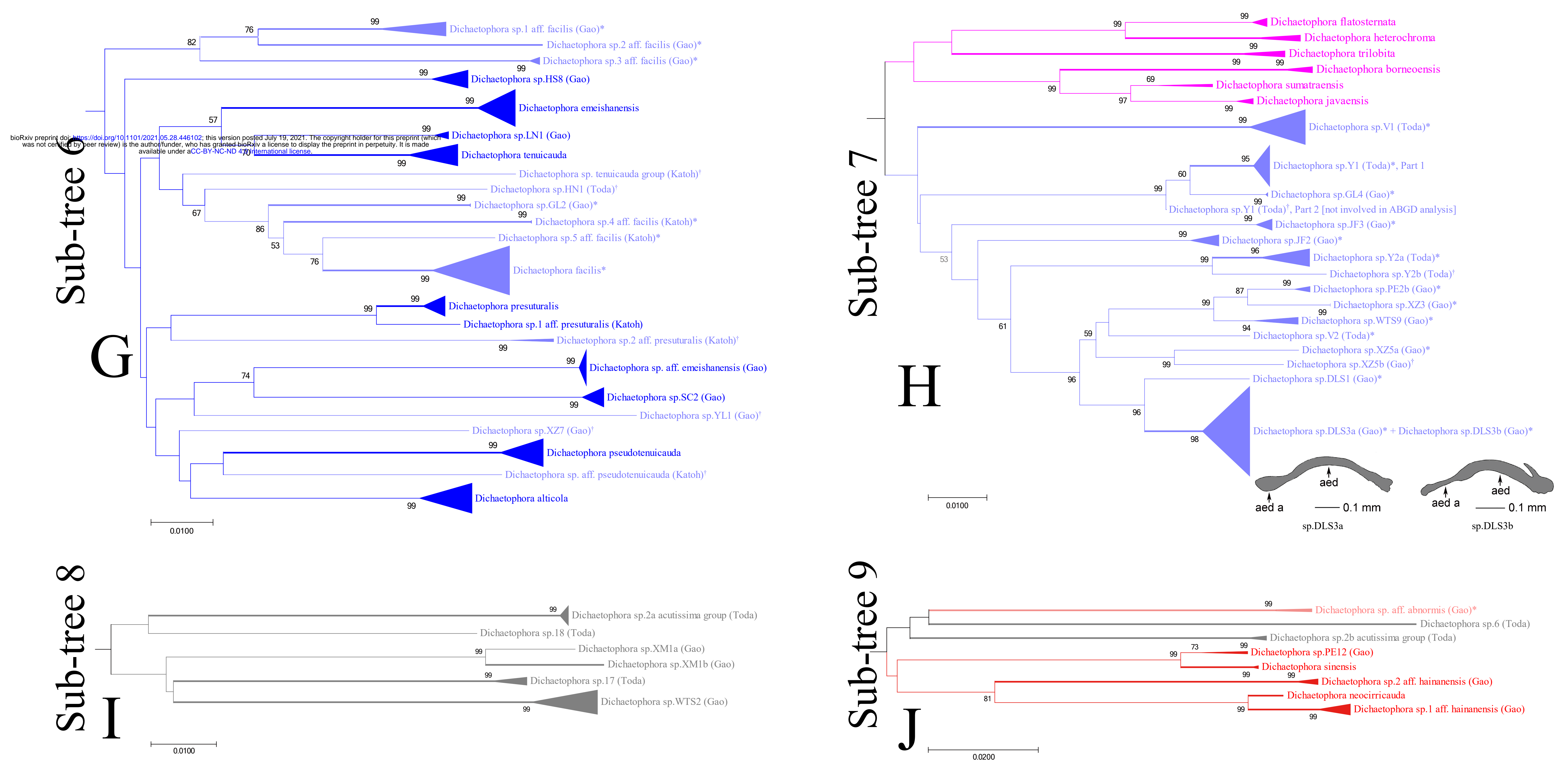


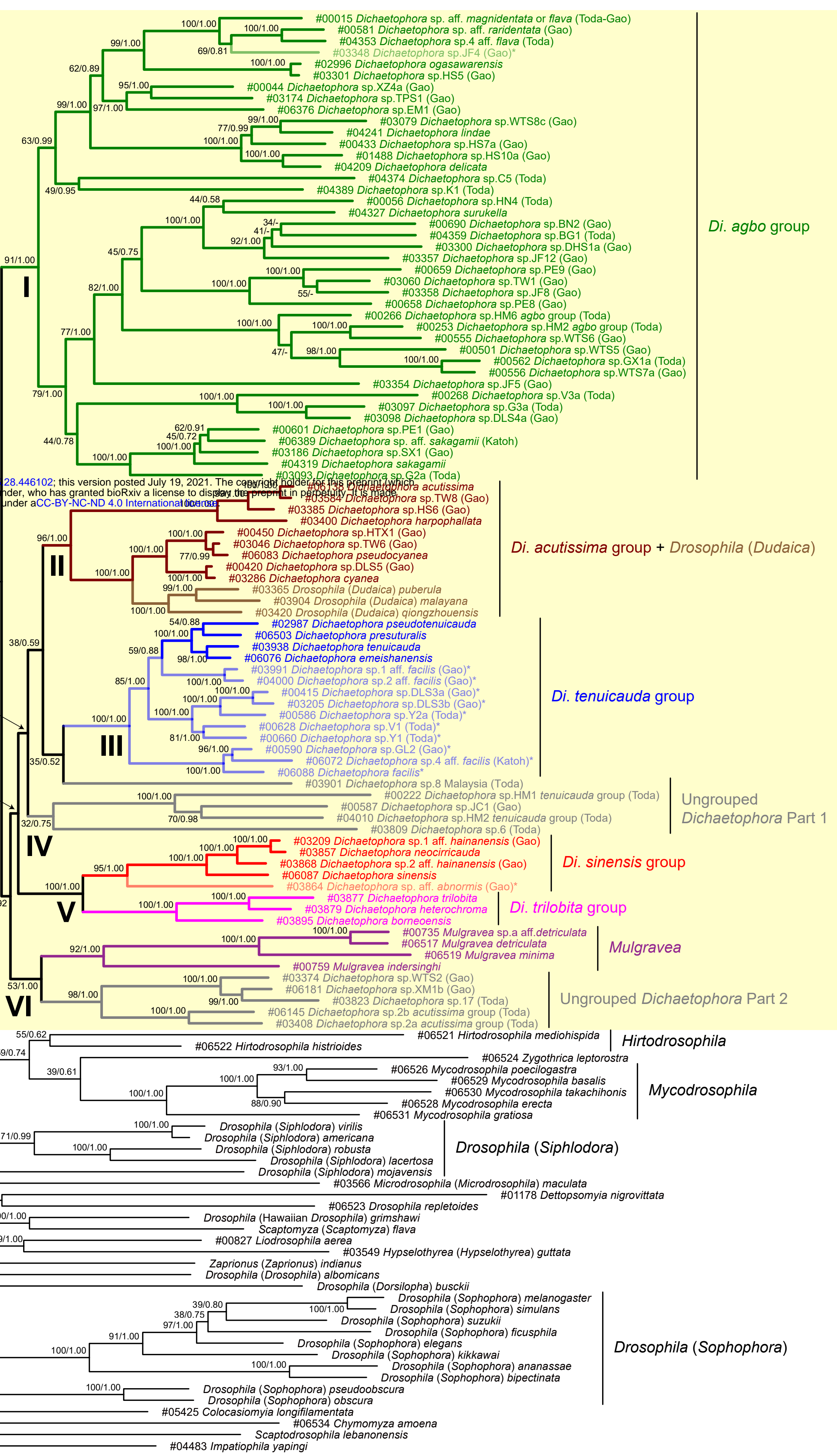

